\title{
ANALISIS ECONÓMICO DEL TERRORISMO
}

\author{
Economic Analysis of Terroriam
}

\section{Paulo Roberto B. Oliveira}

Doutor honoris causa por la Universidad Policial Mariscal Sucre - Estado Plurinacional de Bolívia. Graduación en Derecho por la Universidad del Distrito Federal. Maestria en Derecho por la Universidad de Brasília. Diplomado por la Escuela Superior de Guerra en el Curso de Altos Estudios de Política y Estrategia y en el Curso Superior de Inteligencia Estrategica. Profesor y panelista de la disciplina de Inteligencia Policial; Uso y Empleo de la Fuerza y de Planeamiento Integrado de Operaciones de Protección y Seguridad Interagencias. Desempeñó funciones de investigación de violaciones de derechos humanos por tres años en la División de Derechos Humanos en la Operación de Mantenimiento de Paz de la Organización de las Naciones Unidas en Centro América. Fue Secretario de Estado de Seguridad Pública en el Distrito Federal. Coronel retirado de la Policía Militar. Trabajó en el planeamiento y coordinación de la Protección y Seguridad para los Juegos Olímpicos Rio 2016.

\section{Resumen}

Este artículo tiene como objetivo hacer un análisis económico del Terrorismo y sus implicaciones en las acciones de enfrentamiento por parte del Gobierno especialmente cuando se realizan Grandes Eventos Públicos.

Palabras-clave: Terrorismo. Análisis Económico. Derecho Internacional y Nacional. Doctrina. Grandes Eventos. Brasil.

\section{Abstract}

The objective of this article is to make an economic analysis of Terrorism and its implications in the actions of confrontation by the Government, especially when Big Public Events are held.

Keywords: Terrorism. Economic analysis. Internacional law and nacional law. Big Public events. Brazil.

\section{Sumario}

1. Introdução; 2. Analisis Económico del Terrorismo; 3. Conclusión; 4. Notas; Referencias bibliográficas 


\title{
1. INTRODUÇÃO
}

En los últimos años Brasil recibió Grandes Eventos - Copa de las Confederaciones (2013); la Jornada Mundial de la Juventud (2013); Copa del Mundo FIFA de Fútbol (2014) y los Juegos Olímpicos (2016).

Entre las numerosas variables que involucran la planificación de la seguridad y protección de estos Eventos se destaca la cuestión de la posibilidad de atentados terroristas en el país.

Brasil, en sí, nunca fue objeto de ningún tipo de atentado terrorista internacional, sin embargo la visibilidad de estos Eventos despertó la necesidad de efectuar una planificación detallada y de pronta respuesta si el mismo ocurría en territorio nacional.

Primero. ¿Cómo definir el terrorismo? Hay varios obstáculos para definirlo tales como: percepciones influenciadas por una ideología; religión; opinión política e incluso económica. Crenshaw (2000) alerta que una ausencia de una definición consensuada entre los países hace difícil los estudios sobre el terrorismo.

Sinai (2008) señala que "there is no universally accepted definition that can distinguish attacks against noncombat civilians or military targets, nor does it take into account the latest trends in terrorist practices or their objectives ${ }^{1}$." El mismo autor entiende que el terrorismo es:

\footnotetext{
a combat tactic involving premeditated and politically perpetrated violence by a sub-national group or clandestine agents against any citizen of a State, whether civilian or military, to influence, coerce and, if possible, cause mass casualties and destruction of their targets. ${ }^{2}$
}

Gupta, Clements, Bhattacharya y Chakravarti (2002) traen una posición del United States Code frente la dificultad de una definición universal del tema:

\begin{abstract}
No single definition of terrorism has gained universal acceptance so far. Since the United States has taken the lead in forging a coalition against terrorism following the attacks of September 11, 2001, the definition provided in Title 22 of the United States Code, Section 2656f(d) is presented here first:

- The term "terrorism" means premeditated, politically motivated violence perpetrated against noncombatant targets by subnational groups or clandestine agents, usually intended to influence an audience.

- The term "international terrorism" means terrorism involving citizens or the territory of more than one country.

- The term "terrorist group" means any group practicing, or that has significant subgroups that practice, international terrorism ${ }^{3}$
\end{abstract}

En 1994, la Asamblea General de la Organización de las Naciones Unidas (ONU) adoptó la Resolución 49/60 con el título "Medidas para eliminar el Terrorismo Internacional", donde se hace a una definición genérica del terrorismo que significa la falta, más una vez, de una concertación entre los países:

3. Los actos criminales con fines políticos concebidos o planeados para provocar un estado de terror en la población en general, en un grupo de personas o en personas determinadas son injustificables en todas las circunstancias, cualesquiera sean las consideraciones políticas, filosóficas, ideológicas, raciales, étnicas, religiosas o de cualquier otra índole que se hagan valer para justificarlos;

La misma Resolución también trata del tema del financiamiento del terrorismo internacional así como de que los Estados "deben abstenerse de organizar o instigar actos de ter- 
rorismo en el territorio de otros Estados"; que deben adoptar medidas eficaces en el sentido de "abstenerse de organizar, instigar, facilitar o financiar" el terrorismo:

4. Los Estados, guiados por los propósitos y principios de la Carta de las Naciones Unidas y otras normas pertinentes del derecho internacional, deben abstenerse de organizar o instigar actos de terrorismo en el territorio de otros Estados, de colaborar o participar en su comisión, o de tolerar o alentar que se lleven a cabo en su territorio actividades que apunten a la comisión de esos actos;

5. Los Estados deben asimismo cumplir sus obligaciones en virtud de la Carta de las Naciones Unidas y otras disposiciones de derecho internacional en lo que respecta a la lucha contra el terrorismo internacional y adoptar medidas eficaces y decididas, de conformidad con las disposiciones pertinentes del derecho internacional y las normas internacionales de derechos humanos, con el fin de lograr la eliminación pronta y definitiva del terrorismo internacional y deben en particular:

a) Abstenerse de organizar, instigar, facilitar, financiar, alentar o tolerar actividades terroristas y adoptar medidas prácticas adecuadas para velar por que no se utilicen sus respectivos territorios para instalaciones terroristas o campamentos de adiestramiento o para la preparación u organización de actos terroristas que hayan de perpetrarse contra otros Estados o sus ciudadanos; (sin grifo en el original)

En 1998, con la intensificación del proceso de globalización del sistema financiero internacional el tema del terrorismo se incrementa cuanto a su financiación. Así la Asamblea General de la ONU baja la Resolución 53/108, de 08.12.1998 la cual establece que el Comité Ad Hoc sobre el terrorismo creado por la Resolución 51/210, de 17.12.1996, tenía entre otras funciones elaborar una convención internacional para la supresión del financiamiento del terrorismo.

La Asamblea General indicó que entre los motivos para la creación de un régimen propio para mitigar el financiamiento del terrorismo estaba el facto de que ese era una seria preocupación para la comunidad internacional como un todo. De hecho, también entendía que la gravedad de actos terroristas internacionales dependería de la financiación que los terroristas o su organización podrían obtener y reconoció que los instrumentos internacionales multilaterales aún vigentes no trataban directamente de eses financiamientos.

En 09 de diciembre de 1999, la Asamblea General aprueba la Convención Internacional para la Represión de la Financiación del Terrorismo por la que insta a los Estados Partes a adoptar medidas para prevenir y combatir la financiación directa o indirecta al terrorismo, incluidas las actividades de organizaciones caritativas, sociales y culturales que se utilicen para financiar acciones o grupos terroristas.

\section{$[\ldots]$}

Artículo 2

1. Toda persona comete un delito, de conformidad con lo dispuesto en el presente Convenio, cuando, por cualquier medio, directa o indirectamente, ilegal e intencionalmente, provee o reciba fondos con la intención de emplearlos, o consciente de que los mismos se utilizarán, total o parcialmente, [...]

La Convención todavía obliga a los Estados a responsabilizar penal, civil y administrativamente a los involucrados en todas las etapas y procesar u extraditar acusados de financiar actividades terroristas. 
1. Cada Estado Parte, en el marco de sus principios jurídicos, adoptará las medidas necesarias para que una persona jurídica establecida en su territorio, o organizada de conformidad con su legislación, sea responsabilizada, cuando la persona encargada de la administración o del control de dicha empresa tenga en el ejercicio de su función, cometido uno de los delitos previstos en el Artículo 2. Esta responsabilidad podrá ser de naturaleza criminal, civil o administrativa.

[...]

3. Cada Estado Parte garantizará, en particular, que las personas jurídicas responsables de conformidad con el párrafo 1 anterior, estén sujetas a sanciones penales, civiles o administrativas efectivas, proporcionales y disuasivas. Estas sanciones pueden ser de naturaleza financiera.

Ella también prevé la identificación, bloqueo de cuentas bancarias y la confiscación de fondos destinados a actividades terroristas y la distribución de estos importes entre los Estados afectados. Otro punto importante de la Convención se refiere al secreto bancario que deja de ser una justificación para la negativa de cooperación.

\section{Artículo 8}

1. Cada Estado Parte adoptará las medidas necesarias, de conformidad con sus principios jurídicos internos, para la identificación, detección y congelación o confiscación de cualesquiera fondos empleados o asignados para la comisión de los delitos previstos en el artículo 2, así como de los ingresos resultantes de la comisión de estos delitos, para la eventual incautación.

2. Cada Estado Parte adoptará las medidas necesarias, de conformidad con sus principios internos, para la incautación de los fondos utilizados en la comisión de los delitos previstos en el artículo 2, así como de las rentas derivadas de la comisión de dichos delitos.

3. Cada Estado Parte involucrado podrá considerar la firma de acuerdos para dividir, con otros Estados Partes, en bases regulares o caso por caso, de los fondos provenientes de la incautación a que se refiere el presente artículo.

$[\ldots]$

\section{Artículo 12}

1. Los Estados Partes se prestarán mutuamente la asistencia necesaria para fines de investigaciones penales o procesos penales o de extradición en lo que se refiere a los delitos previstos en el Artículo 2, incluida la asistencia en la obtención de pruebas en su poder necesarias para el curso del proceso.

2. Los Estados Partes no podrán rechazar solicitudes de asistencia mutua bajo la afirmación de secreto bancario.

En 2004, diez años después de la Resolución 49/60, el Consejo de Seguridad de la ONU aprobó la Resolución 1.566/2004 que vuelve a tratar del tema terrorismo:

3. Recuerda que los actos criminales, inclusive contra civiles, cometidos con la intención de causar la muerte o lesiones corporales graves o de tomar rehenes con el propósito de provocar un estado de terror en la población en general, en un grupo de personas o en determinada persona, intimidar a una población u obligar a un gobierno o a una organización internacional a realizar un acto, o a abstenerse de realizarlo, que constituyen delitos definidos en los convenios, las convenciones y los protocolos internacionales relativos al terrorismo y comprendidos en su ámbito, no admiten justificación en circunstancia alguna por consideraciones de índole política, filosófica, ideológica, racial, étnica, religiosa u otra similar e insta a todos los Estados a prevenirlos y, si ocurren, a cerciorarse de que sean sancionados con penas compatibles con su grave naturaleza;

La misma Resolución aún "insta a todos los Estados a que, de conformidad con las obligaciones que les impone el derecho internacional, cooperen plenamente en la lucha contra el terrorismo" en especial contra aquellos "a quien apoye o facilite la financiación, la planificación, la preparación o la comisión de actos de terrorismo" (sin grifo en el original). Nuevamente la preocupación de la ONU a respeto de la financiación de actos terroristas. 
De esa manera, tanto la Asamblea cuanto el Consejo tienen la idea clara de que acciones violentas contra blancos indiscriminados con el objetivo de intimidar una población u obligar Gobiernos a hacer o dejar de hacer alguna cosa es terrorismo. De igual manera la preocupación permanente con el financiamiento de actos de terror $u$ organizaciones terroristas están presentes en las dos Resoluciones.

En el ámbito de la Unión Europea (UE) existen dos marcos legales importantes: la Convención Europea para la Represión del Terrorismo, de 27.01.1977, y la Convención para la Prevención del Terrorismo, de 16.05.2017. Sin embargo, el mayor avance se produjo a través de una decisión del Consejo de Europa que buscó "una aproximación de la definición de los delitos de terrorismo en los Estados miembros, incluidos los delitos relativos a los grupos terroristas". La Decisión Marco del Consejo, de 13 de junio de 2002, sobre la lucha contra el terrorismo logró un acuerdo inédito de los países de la UE sobre una definición unánime del asunto en dos puntos - (i) estableció en el artículo 1 los actos que se consideran delitos de terrorismo y (ii) en su artículo 2 el entendimiento por "grupo terrorista":

Artículo 1 Delitos de terrorismo y derechos y principios fundamentales

1. Todos los Estados miembros adoptarán las medidas necesarias para que se consideren delitos de terrorismo los actos intencionados a que se refieren las letras a) a i) tipificados como delitos según los respectivos Derechos nacionales que, por su naturaleza o su contexto, puedan lesionar gravemente a un país o a una organización internacional cuando su autor los cometa con el fin de:

— intimidar gravemente a una población,

- obligar indebidamente a los poderes públicos o a una organización internacional a realizar un acto o a abstenerse de hacerlo,

- o desestabilizar gravemente o destruir las estructuras fundamentales políticas, constitucionales, económicas o sociales de un país o de una organización internacional;

a) atentados contra la vida de una persona que puedan tener resultado de muerte;

b) atentados graves contra la integridad física de una persona;

c) secuestro o toma de rehenes;

d) destrucciones masivas en instalaciones gubernamentales o públicas, sistemas de transporte, infraestructuras, incluidos los sistemas informáticos, plataformas fijas emplazadas en la plataforma continental, lugares públicos o propiedades privadas, que puedan poner en peligro vidas humanas o producir un gran perjuicio económico;

e) apoderamiento ilícito de aeronaves y de buques o de otros medios de transporte colectivo o de mercancías;

f) fabricación, tenencia, adquisición, transporte, suministro o utilización de armas de fuego, explosivos, armas nucleares, biológicas y químicas e investigación y desarrollo de armas biológicas y químicas;

g) liberación de sustancias peligrosas, o provocación de incendios, inundaciones o explosiones cuyo efecto sea poneren peligro vidas humanas;

h) perturbación o interrupción del suministro de agua, electricidad u otro recurso natural fundamental cuyo efecto sea poneren peligro vidas humanas;

i) amenaza de ejercer cualesquiera de las conductas enumeradas en las letras a) a h).

[...]

Artículo 2 Delitos relativos a un grupo terrorista

1. A efectos de la presente Decisión marco, se entenderá por «grupo terrorista» toda organización estructurada de más de dos personas, establecida durante cierto período de tiempo, que actúa de manera concertada con el fin de cometer delitos de terrorismo. Por «organización estructurada» se en- 
tenderá una organización no formada fortuitamente para la comisión inmediata de un delito y en la que no necesariamente se ha asignado a sus miembros funciones formalmente definidas ni hay continuidad en la condición de miembro o una estructura desarrollada. (sin grifo en el original)

La misma Decisión también trató de la financiación del terrorismo en el ítem 2 del artículo 2:

2. Todos los Estados miembros adoptarán las medidas necesarias para tipificar como delitos los actos intencionales siguientes: a) dirección de un grupo terrorista; b) participación en las actividades de un grupo terrorista, incluido el suministro de información o medios materiales, o mediante cualquier forma de financiación de sus actividades, con conocimiento de que esa participación contribuirá a las actividades delictivas del grupo terrorista. (sin grifo en el original)

Solamente en 2005, Brasil adoptó la Convención Internacional para la Represión de la Financiación del Terrorismo por medio del Decreto Federal 5.640. de 26.12.2005, determinando que ella sea ejecutada y cumplida tan enteramente como en ella se contiene. También estableció que ejercerá jurisdicción sobre todas las hipótesis previstas en los apartados "a", "b", "c", "d" e "y" del artículo 7, párrafo 2, de la Convención, tal como se establece en el párrafo 3 del mismo artículo.

En este sentido, en que pese ser signatario de diversos instrumentos internacionales, hasta el año 2016 Brasil no contenía en su ordenamiento jurídico infra constitucional de una previsión legal específica para el enfrentamiento del terrorismo. La Constitución de 1988 trataba del tema solamente en una parte: art. $5^{\circ}$, XLIII como un crimen sin posibilidad de fianza y no susceptible de gracia o amnistía.

Subsidiariamente se utilizaba la Ley Federal 12.850, de 02/08/2013, que trata de las organizaciones criminales la cual fue modificada incluyendo el párrafo $2^{\circ}$ en su artículo $1^{\circ}$ la posibilidad de que organizaciones terroristas internacionales fueran combatidas de la misma manera de las organizaciones criminales:

[...] as organizações terroristas internacionais, reconhecidas segundo as normas de direito internacional, por foro do qual o Brasil faça parte, cujos atos de suporte ao terrorismo, bem como os atos preparatórios ou de execução de atos terroristas, ocorram ou possam ocorrer em território nacional.

El caso se resolvió a partir de la Ley Federal 13.260, de 16/03/2016 que se quedó conocida cómo la Ley anti terrorismo (LAT). Esta Ley está de acuerdo con el Derecho Internacional.

De ese modo, se aclaró que el terrorista no se confunde con un criminoso común. El objetivo del terrorista es amenazar y causar daños a toda la sociedad, promover el pánico, crear dificultades a orden institucional y social. Por su vez, el criminoso común tiene como objetivo el lucro con su conducta criminal. Interesante observar que el atentado terrorista tiene como objetivo atentar contra un gobierno ó/y la sociedad civil en general.

Una de las bases de las organizaciones terroristas se refiere al dinero que estas consiguen generar en razón de negocios propios (por ejemplo: la explotación de petróleo realizada por ISIS en territorio por él ocupado); a partir de donaciones realizadas por personas; organizaciones e incluso gobiernos simpatizantes de la causa. 
En este sentido, es fundamental buscar la neutralización de esos mecanismos de financiamiento por medio de medidas legales con el objetivo de bloquear cuentas; confiscar bienes e impedir el flujo de dinero para subsidiar acciones terroristas.

La LAT estableció mecanismos muy importantes para el enfrentamiento del terrorismo a partir del flujo económico. Así, el financiamiento del terrorismo es tratado en el artículo $6^{\circ}$ :

Art. $6^{\circ}$ Receber, prover, oferecer, obter, guardar, manter em depósito, solicitar, investir, de qualquer modo, direta ou indiretamente, recursos, ativos, bens, direitos, valores ou serviços de qualquer natureza, para o planejamento, a preparação ou a execução dos crimes previstos nesta Lei:

Pena - reclusão, de quinze a trinta anos.

De la misma forma, la LAT trató del soporte económico y financiero a las organizaciones terroristas por medio del artículo 12:

Art. 12. O juiz, de ofício, a requerimento do Ministério Público ou mediante representação do delegado de polícia, ouvido o Ministério Público em vinte e quatro horas, havendo indícios suficientes de crime previsto nesta Lei, poderá decretar, no curso da investigação ou da ação penal, medidas assecuratórias de bens, direitos ou valores do investigado ou acusado, ou existentes em nome de interpostas pessoas, que sejam instrumento, produto ou proveito dos crimes previstos nesta Lei.

$\S 1^{\circ}$. Proceder-se-á à alienação antecipada para preservação do valor dos bens sempre que estiverem sujeitos a qualquer grau de deterioração ou depreciação, ou quando houver dificuldade para sua manutenção.

$\S 2^{\circ}$. O juiz determinará a liberação, total ou parcial, dos bens, direitos e valores quando comprovada a licitude de sua origem e destinação, mantendo-se a constrição dos bens, direitos e valores necessários e suficientes à reparação dos danos e ao pagamento de prestações pecuniárias, multas e custas decorrentes da infração penal.

$\S 3^{\circ}$. Nenhum pedido de liberação será conhecido sem o comparecimento pessoal do acusado ou de interposta pessoa a que se refere o caput deste artigo, podendo o juiz determinar a prática de atos necessários à conservação de bens, direitos ou valores, sem prejuízo do disposto no $\S 1$.

$\S 4^{\circ}$. Poderão ser decretadas medidas assecuratórias sobre bens, direitos ou valores para reparação do dano decorrente da infração penal antecedente ou da prevista nesta Lei ou para pagamento de prestação pecuniária, multa e custas.

El artículo 13 de la LAT se refiere a los procedimientos para la administración de bienes, derechos y valores de terroristas o de sospechosos de terrorismo y sujetos de medidas que puedan asegurar una posible indemnización a víctimas.

Art. 13. Quando as circunstâncias o aconselharem, o juiz, ouvido o Ministério Público, nomeará pessoa física ou jurídica qualificada para a administração dos bens, direitos ou valores sujeitos a medidas assecuratórias, mediante termo de compromisso.

Aún en el campo económico, la LAT trae la posibilidad de cumplimiento de acuerdos internacionales que se refieran a bienes, derechos o valores oriundos de organizaciones terroristas. En este aspecto, la LAT atiende las demandas de la comunidad internacional con respecto a una actuación más incisiva de Brasil en el enfrentamiento del terrorismo y en la cooperación con otros países y organizaciones internacionales.

Art. 15. O juiz determinará, na hipótese de existência de tratado ou convenção internacional e por solicitação de autoridade estrangeira competente, medidas assecuratórias sobre bens, direitos ou valores oriundos de crimes descritos nesta Lei praticados no estrangeiro.

$\S 1^{\circ}$. Aplica-se o disposto neste artigo, independentemente de tratado ou con- 
venção internacional, quando houver reciprocidade do governo do país da autoridade solicitante.

$\S 2^{\circ}$. Na falta de tratado ou convenção, os bens, direitos ou valores sujeitos a medidas assecuratórias por solicitação de autoridade estrangeira competente ou os recursos provenientes da sua alienação serão repartidos entre o Estado requerente e o Brasil, na proporção de metade, ressalvado o direito do lesado ou de terceiro de boa-fé.

\section{ANALISIS ECONÓMICO DEL TERRORISMO}

De acuerdo con los datos compilados por el Institute for Economics \& Peace (IEP) los costos económicos mundiales del terrorismo se encuentran en el nivel más alto desde 2001. Según el IEP se estima que en 2014 los costos económicos mundiales del terrorismo alcanzaron los US \$ 52.900 millones, con un impacto económico total de US \$ 105.800 millones. Esto se calculó utilizando la metodología del costo económico de la violencia del IEP, que mide los costos directos e indirectos de la pérdida de vidas, la destrucción de propiedades y las pérdidas por el pago de rescates. El impacto económico se refiere a los costos directos e indirectos en el año actual representados en US \$ constantes de 2014.

\section{FIGURE 34 THE COSTS OF TERRORISM, US\$ BILLIONS, 2000-2014}

Based on IEP's methodology, the global economic costs of terrorlsm reached the highest ever level in 2015 at $\$ 52.9$ billion. Figures reported in constant 2014 US $\$$ billions.

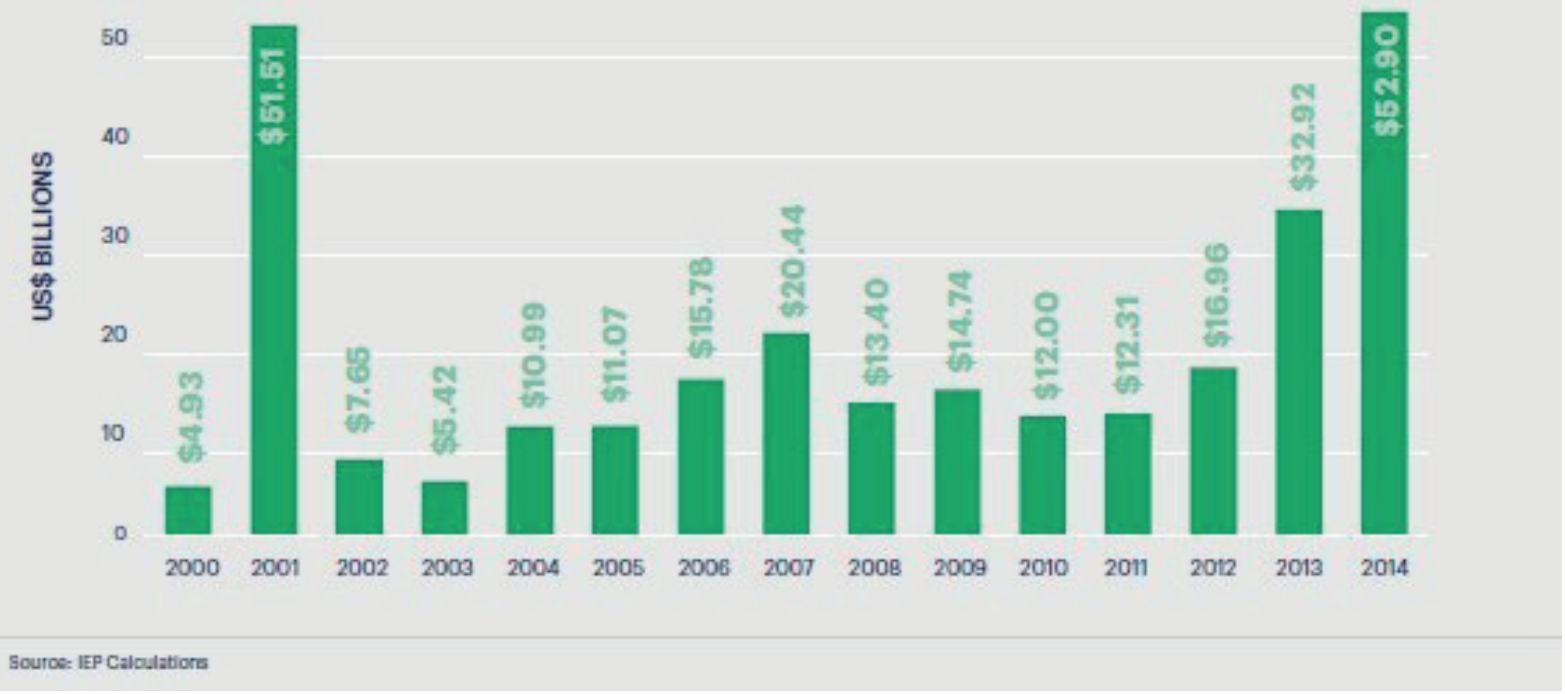

Fuente: IEP. GLOBAL TERRORISM INDEX 2015 Economic Costs of Terrorism.

El cuadro presentado a continuación con origen en el mismo Informe de la IEP detalla las pérdidas económicas por categorías en el año 2014. 


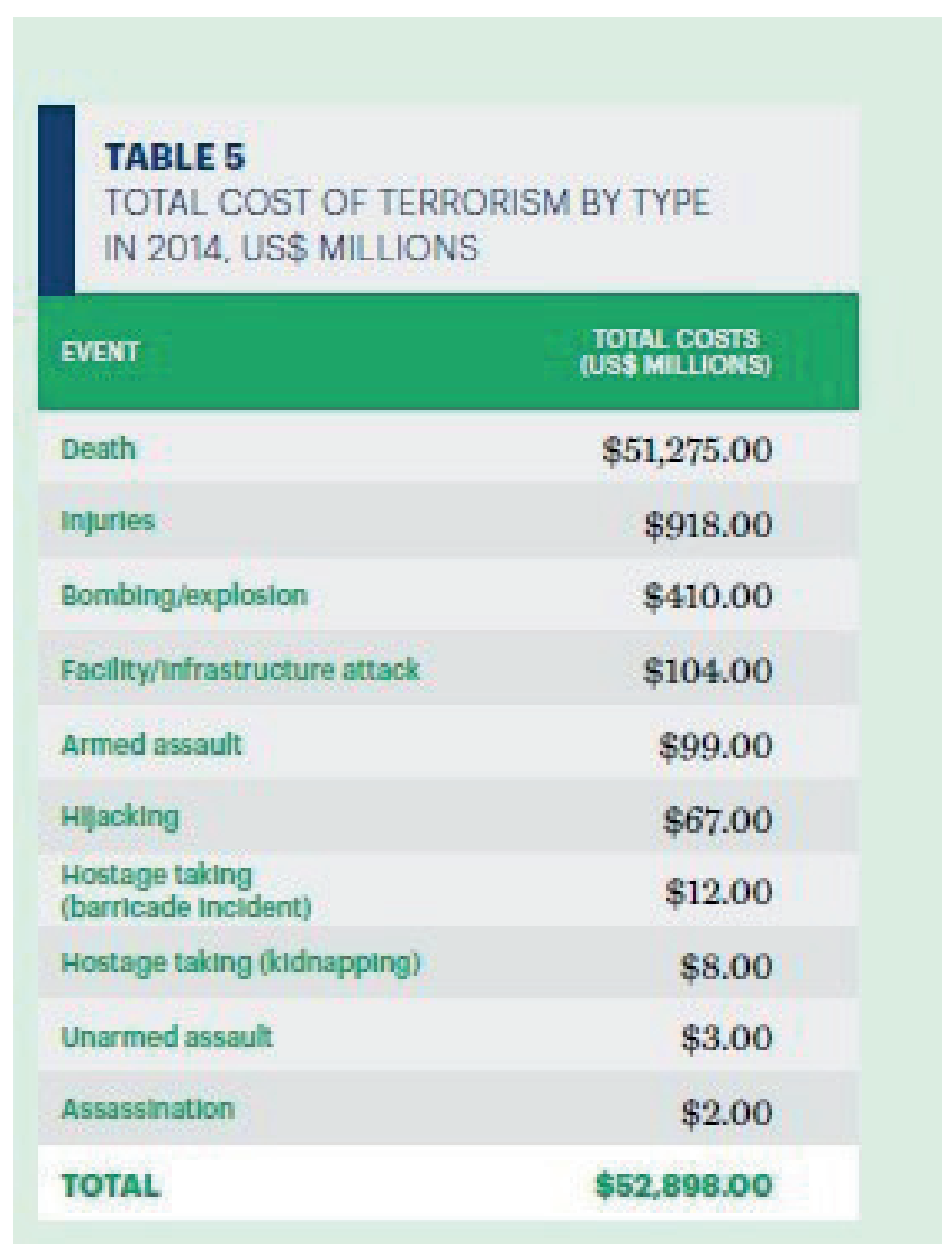

Fuente: IEP. GLOBAL TERRORISM INDEX 2015 Economic Costs of Terrorism.

Brauer (2002) al analizar el comportamiento racional de una organización terrorista, indica entre otros:

a. Se asignarán recursos para minimizar los gastos y maximizar los resultados. Indica que los atentados con explosivos son más baratos y alcanzan a más personas y bienes, luego son más eficientes, por lo que son más utilizados.

b. El acto de terror deriva de una elección entre un comportamiento racional legal y un ilegal. No existiendo campo para la negociación la motivación será para un comportamiento ilegal.

c. Cuando el Estado aumenta el costo de determinado comportamiento, los grupos terroristas van a sustituir estos actos por otros menos costosos. Por ejemplo, cuando el Gobierno instala equipos electrónicos de detección en los aeropuertos, los terroristas buscan nuevos objetivos, tales como edificios públicos, terminales de autobús, etc.

d. La existencia de gran número de personas disponibles para el reclutamiento minimiza los costos de atentados que utilizan personas, especialmente si el pago es inmaterial, tal como la vida eterna en el paraíso.

e. Los medios de comunicación atraen la atención de los terroristas. Funciona como una propaganda gratuita.

f. Algunos Estados pueden considerar dar refugio a terroristas a cambio de la paz doméstica.

Pillar (2001) considera que es fundamental que los Estados aumenten los costos de una acción terrorista con la adopción de medidas anti terroristas. Prosigue el autor manifestando que el comportamiento del terrorista obedece a una lógica y sus actividades tienen costos y beneficios que son analizados por la organización que lo conduce. Las políticas de 
Gobierno que caminan en esta dirección pueden ser más efectivas en el enfrentamiento de terroristas.

El terrorismo visto como un crimen tiene un enfoque económico. Becker (1968) ya desarrollaba estudios del fenómeno criminal desde su trabajo en "Crime and Punishment: an economic Aprroach". De este modo el comportamiento delictivo está motivado por factores relacionados con los costos y beneficios de su acto.

El terrorista, como ya se ha demostrado, no es un criminal común. Brauer (2002) entiende que la análisis de los costos para los terroristas puede tener como elementos los gastos financieros para la comisión de atentados, la probabilidad de ser arrestados o muertos, la clandestinidad, los gastos de propaganda y divulgación, etc. Así, es fundamental que en el enfrentamiento al terrorismo el Estado adopte medidas que aumente significativamente los costos de un atentado o incluso de una acción terrorista.

Como ejemplos de estas acciones gubernamentales y siguiendo la experiencia de este autor en la coordinación de la planificación de la protección y seguridad de los Grandes Eventos en Brasil se ha aumentado la protección de blancos potencialmente subsidiarios, aumento de los mecanismos de control en áreas de seguridad previamente definidos, disminución de la posibilidad de obtención de recursos por las organizaciones terroristas, reducción del reclutamiento, inversión en un aparato de Inteligencia que permita a las Instituciones de Gobierno la prevención contra esas amenazas, su identificación y posible neutralización antes de que actúen etc.

Con base en los estudios matemáticos desarrollados por Viapiana (2006) Gonçalves

\section{COSTO X BENEFÍCIO DEL TERRORISMO}

y Reis (2016) construyeron una función que correlaciona el costo x beneficios del terrorismo.

$$
\begin{gathered}
\mathbf{T}=\mathbf{B}-(\mathbf{P} \times \mathbf{C}) \\
\text { donde } \\
\mathbf{T}=\text { Beneficio }-(\text { Probabilidad de punición } \times \text { Costos }) \\
\text { en que } \\
\text { Terror }>0=\text { vale la pena el atentado } \\
\text { Terror }<0=\text { no vale la pena el atentado }
\end{gathered}
$$

Fuente: Gonçalves y Reis con base nos estudios de Viapiana.

Según los autores, es responsabilidad del Estado influenciar esta ecuación, reduciendo los beneficios y aumentando los costos con el objetivo de desmotivar acciones terroristas. En este sentido, las acciones gubernamentales deben tender al aumento de la probabilidad de prisión o de neutralización del terrorista o disminuir la posibilidad de recursos en dinero y consecuentemente elevar los costos de un atentado terrorista. Por obvio que atentados 
suicidas alejan el riesgo de prisión y por eso son muy utilizados por las organizaciones terroristas. Llussá y Tavares (2007) havian Ilegado la misma conclusión "The use of suicide bombers has become more frequent".

Otro punto importante de la financiación del terrorismo, frente la creación de instrumentos jurídicos internacionales que dificultan el financiamiento de sus acciones, se refiere a una modalidad que puede contornar, evitar el sistema de control de los Gobiernos siendo de difícil detección: el sistema conocido como Hawalas.

El sistema hawala es uno de los Sistemas de Transferencia Informal de Fondos (IFT) que se utilizan en muchas regiones para transferir fondos, tanto a nivel nacional como internacional. El sistema hawala como IFT existe bajo diferentes nombres en diversas regiones del mundo. Por ejemplo: Fei-Ch'ien (China), Padala (Filipinas), Hundi (India), Hui Kuan (Hong Kong) y Phei Kwan (Tailandia).

El Hawalas es un mecanismo de transferencia de fondos basados en la confianza y que no transitan por el sistema financiero tradicional. Comprende operaciones monetarias realizadas en agencias de remesas de dinero basadas en la confianza popular, particularmente en las comunidades de origen musulmán, en el caso del terrorismo, las operaciones llevadas a cabo en los países de Asia; África y América del Sur. Con un simple apretón de manos y el establecimiento de un código, los individuos son capaces de transferir dinero en todo el mundo. Al encaminarse a una agencia Hawala, el emisor concede el recurso monetario al operador y el dinero, en pocos minutos, aparece en otro país la disposición de la persona que posea el código. Así el dinero no se mueve por el sistema financiero, sino que ha existido una compensación de fondos existentes en los dos lugares, de origen y de destino.

Mohammed El-Qorchi (2002) indica que después del 11 de septiembre de 2001 hubo un aumento del interés público en los Sistemas Informales de Transferencia de dinero en todo el mundo, particularmente el Sistema Hawala.

Para el autor "la razón es el supuesto papel del sistema hawala en el financiamiento de actividades ilegales y terroristas, junto con su papel tradicional de transferir dinero entre individuos y familias, a menudo en diferentes países".

Prosigue haciendo una distinción importante: el sistema hawala del término hawala. El sistema hawala se refiere a un canal informal para transferir fondos de un lugar a otro a través de proveedores de servicios, conocidos como "hawaladars", independientemente de la naturaleza de la transacción y los países involucrados, mientras que el término hawala significa "transferencia" o "cable" en la jerga bancaria árabe.

El autor entiende que si bien el hawala se utiliza para la transferencia legítima de fondos, su anonimato y documentación mínima también lo han hecho vulnerable al abuso por parte de personas y grupos que transfieren fondos para financiar actividades ilegales de todo tipo y concluye:

A pesar de su informalidad, el sistema hawala tiene implicaciones macroeconómicas directas e indirectas, tanto para la actividad financiera como para el desempeño fiscal. Un aspecto es su impacto potencial en las cuentas monetarias de los países en cualquiera de los extremos de la transacción hawala. Debido a que estas transacciones no se reflejan en las estadísticas oficiales, el envío de 
fondos de un país a otro no se registra como un aumento en los activos externos del país receptor o en los pasivos del país remitente, a diferencia de los fondos transferidos a través del sector formal. Como consecuencia, el valor cambia de manos, pero el dinero en sentido amplio no se altera. Sin embargo, las transacciones de hawala pueden afectar la composición del dinero en sentido amplio en un país receptor. En el negocio de remesas, tales transacciones se realizan principalmente en efectivo, aunque los hawaladars pueden usar el sistema bancario para otros fines. Las personas de países en desarrollo que transfieren fondos al exterior a través del sistema hawala para fines de inversión o de otro tipo suelen ser miembros de grupos adinerados. Suministran hawaladars locales con efectivo haciendo retiros de sus cuentas bancarias. Como consecuencia, las transacciones tipo hawala tienden a aumentar la cantidad de efectivo en circulación.

\section{Grupta, Clements, Bhattacharya y Chakravarti (2002) en el artículo "Fiscal Conse- quences of Armed Conflict and Terrorism in Low- and Middle-Income Countries" indican que \\ Contrary to expectations, the end of the Cold War has not been a harbinger of peace. There has been a proliferation of armed conflicts around the world over the past dozen years. In particular, terrorist groups have become increasingly sophisticated, daring, and destructive ${ }^{5}$.}

Para los autores tanto los conflictos armados como las actividades terroristas pueden influir fuertemente en los ingresos y los gastos de los Gobiernos y, a su vez, afectar directamente el crecimiento económico de los países.

Según los autores el terrorismo puede afectar las cuentas fiscales al interrumpir las actividades económicas, erosionando la base impositiva, disminuyendo la eficiencia de la administración tributaria y distorsionando la composición del gasto público. Continúan indicando que "las recesiones económicas debido a la inseguridad y la violencia pueden conducir a una disminución de los ingresos fiscales". Para los autores "más allá de sus efectos sobre la actividad real" el terrorismo puede destruir parte de la base tributaria (por ejemplo, la destrucción de empresas comerciales y de turismo) y "debilitar la eficiencia de la administración tributaria".

Mesquita (2008) entiende que es difícil responder empíricamente: ¿cuál es el efecto del terrorismo en la economía de un país? debido la existencia de muchas variables. Por ejemplo (i) directas: las vidas productivas perdidas, infraestructura destruida, interrupciones en el trabajo, etc. (incluso si puede formar estimaciones razonables de estos efectos directos) y (ii) indirectos: pérdida de tiempo y eficiencia para aumentar la seguridad aeroportuaria; pérdida de los impuestos necesarios para realizar pagos a las víctimas de los ataques; a corto plazo devaluación en el mercado debido a cambios en el rendimiento esperado y el riesgo, y así sucesivamente, que son considerablemente más difíciles de medir, según el autor.

De otra parte, el mismo autor indica que cuando los estudios se refieren a puntos de la actividad económica o localidades específicas hay una mayor precisión de los costos.

More precise estimates of the impact of terrorism on the economy are to be had from studies of longer-run (though less intense) terrorist conflicts. Such studies have taken two forms: focusing either on specific types of economic activity or on the economy of a specific country. With regard to the former, Abadie and Gardeazabal (2005) argue that terrorism affects the allocation of investment capital by increasing risk and decreasing expected returns. Their estimates indicate that increased terrorism risk in a country significantly decreases foreign direct investment in that country. Enders and Sandler (1996) also find large negative effects of terrorism on foreign direct investment in Greece and Spain. Similarly, Enders, Sandler and Parise (1992) find that terrorism significantly reduces tourism in Greece, Italy, and Austria. Similarly, Enders, Sandler and Parise (1992) find that 
terrorism significantly reduces tourism in Greece, Italy, and Austria 6 .

Two recent studies estimate the effect of terrorism on economic growth in particular conflict zones. Abadie and Gardeazabal (2003) consider how ETA terrorism has diminished economic growth in the Basque Country of Spain. They are able to do so because ETA terrorism has been overwhelmingly concentrated in this one region. Given this, they statistically construct a "synthetic" Basque Country based on other Spanish regions and compare its growth (free from terrorism) to the growth of the actual Basque Country. Their analysis suggests that ETA terrorism has decreased per capita GDP in the Basque Country by 10 percentage points since the onset of Basque terrorism in the 1960s. Eckstein and Tsiddon (2004) employ an intervention-style time series methodology to study the effects of terrorist attacks on the Israeli economy. They find that terrorism depresses growth, but that the effects of any given attack are relatively short lived ${ }^{7}$.

Eldor y Melnick (2004) analizó el impacto de los ataques terroristas palestinos sobre los precios del mercado de valores y los tipos de cambio en Israel utilizando datos diarios de series temporales de 1990 hasta 2003.

Según los autores, cuando fue intensificado los ataques terroristas palestinos, después del 27 de septiembre de 2000, estos tuvieron un efecto negativo permanente en el mercado de valores, pero no en el mercado de moneda extranjera. El declive del mercado de acciones indicó que, además de la pérdida de vidas y lesiones personales a las víctimas, los ataques terroristas tuvieron costos económicos reales que redujeron los beneficios esperados de las empresas.

Concluyen sus estudios indicando que todavía los mercados financieros continuaron desempeñando sus funciones económicas de manera eficiente:

We find that markets are efficient in incorporating the news of terror attacks and find no evidence that markets became desensitized to terror attack over time. Our principal conclusion is that financial markets continued to perform their economic functions in an efficient way ${ }^{8}$.

Llussá y Tavares (2007) indican que, después del atentado terrorista del 11 de septiembre de 2001, hubo un incremento de estudios que pretendían verificar el impacto del terrorismo en la economía: "A large number of studies focus on measuring the economy-wide impact of terrorist attacks ${ }^{9 "}$. Para los autores, los estudios indicaron que las acciones terroristas tenían un costo más bajos que los conflictos internos, las guerras o desastres naturales: "They conclude that the direct cost to output is relatively small, smaller than the cost of internal conflict, external war, or natural disasters ${ }^{10}$ ". Mesquita (2008) concuerda con el posicionamiento de Llussá y Tavares que también indican que "Nonetheless, for specific populations, regions, and sectors the adverse effects can be very large ${ }^{11 "}$.

Los autores manifiestan la necesidad de coordinación e integración multilateral para la disuasión de los actos terroristas:

As terrorists substitute among means, targets, and across time, counterterrorist strategies beyond deterrence, such as comprehensive multilateral coordination, must be developed and applied ${ }^{12}$.

En este contexto, los gobiernos y los organismos internacionales han intentado desarrollar una mejor comprensión del terrorismo y de los Sistemas de Transferencia Informal de Fondos, especialmente el Hawala, evaluar sus implicaciones económicas y normativas y diseñar el enfoque más apropiado para abordarlos bien como el impacto económico real (directa e indirecta) de acciones terroristas en sus países. 


\section{CONCLUSIÓN}

Según IEP a medida que aumenta la actividad terrorista, la inseguridad dentro de las sociedades también aumenta cuando los gobiernos responden incrementando el gasto en la aplicación de la lucha contra el terrorismo, especialmente para las Agencias de Seguridad y la Fuerza Armada.

El IEP estima que entre 2001 y 2014 el gasto de las agencias de seguridad domésticas en los Estados Unidos ha sido de 1,1 billones de dólares, un promedio de 73000 millones de dólares al año. Si bien el gasto de las agencias de seguridad nacional no está totalmente dedicado a la lucha contra el terrorismo, es un componente principal de la mayoría de las agencias de inteligencia en el mundo desarrollado. Se estima que el $44 \%$ de los gastos de los organismos de seguridad internos de los Estados Unidos están dedicados a la lucha contra el terrorismo.

En el Reino Unido, el $81 \%$ del presupuesto de recursos del MI5 está dedicado a la lucha contra el terrorismo nacional e internacional. El gasto del MI5 en actividades antiterroristas relacionadas con Irlanda del Norte por sí solo ascendió a más de US \$2,28 mil millones en 2014.

De hecho, las organizaciones terroristas siguen una estrategia determinada con el fin de cambiar la realidad según una orientación ideológica. El terrorismo es la táctica para alcanzar objetivos previamente determinados.

La financiación del terrorismo, expuesta en este artículo, es una preocupación permanente en el ámbito internacional. Una de las formas más eficientes de enfrentar el terrorismo será la retirada de su capacidad financiera.

Los grupos terroristas así como las organizaciones criminales sin recursos financieros adquieren una probabilidad menor de efectuar sus acciones e incluso de atraer y entrenar a personas o grupos.

En respuesta a la creciente preocupación por el lavado de dinero que amenazaba el sistema bancario y las instituciones financieras, la Cumbre del G-7, que se celebró en Paris en 1989, estableció el "Financial Action Task Force" (FATF). Inicialmente, integró el Grupo de Trabajo los Estados miembros del G-7, la Comisión Europea y otros ocho países. Actualmente integran al FATF 37 países y dos organizaciones regionales ${ }^{13}$, representando la mayoría de los principales centros financieros en todas partes del mundo.

Los objetivos del FATF-GAFI son establecer estándares y promover la implementación efectiva de medidas legales, regulatorias y operacionales para combatir el lavado de dinero, el financiamiento del terrorismo y otras amenazas relacionadas a la integridad del sistema financiero internacional. El FATF-GAFI es, por lo tanto, un "órgano de formulación de políticas" que trabaja para generar la voluntad política necesaria para llevar a cabo reformas legislativas y regulatorias nacionales en estas áreas.

EI FATF-GAFI ha desarrollado una serie de Recomendaciones que están reconocidas como el estándar internacional para combatir el lavado de dinero y el financiamiento del 
terrorismo y la proliferación de armas de destrucción masiva: International Standard son Combating Money Laundering and the Financing of Terrorism \& Proliferation - the FATF Recommendations ${ }^{14}$.

El factor económico puede ser un arma poderosa para la toma de decisiones en políticas públicas de seguridad e Inteligencia en especial na prevención y enfrentamiento a acciones terroristas. La inversión en la capacitación de agentes públicos con el fin de efectuar un análisis económico del fenómeno es indubitablemente un sendero necesario y primordial: impedir y localizar los flujos económicos de las organizaciones terroristas con el objetivo de que el dinero no sea aportado tanto para la organización cuanto para sus integrantes.

\section{NOTAS}

1. Traducción libre: «no existe una definición universalmente aceptada que pueda distinguir los ataques contra civiles no combatientes o objetivos militares, ni toma en cuenta las últimas tendencias en prácticas terroristas o sus objetivos».

2. Traducción libre: «una táctica de combate que involucra violencia premeditada y políticamente perpetrada por un grupo subnacional o agentes clandestinos contra cualquier ciudadano de un Estado, ya sea civil o militar, para influenciar, coaccionar y, si posible, causar bajas masivas y destrucción de sus blancos».

3. Traducción libre: Ninguna definición única de terrorismo ha ganado aceptación universal hasta ahora. Dado que los Estados Unidos han tomado la delantera para forjar una coalición contra el terrorismo tras los ataques del 11 de septiembre de 2001, la definición que se proporciona en el Título 22 del Código de los Estados Unidos, Sección $2656 f$ (d) se presenta aquí primero:

- El término "terrorismo" significa violencia premeditada y motivada políticamente perpetrada contra objetivos no combatientes por grupos subnacionales o agentes clandestinos, generalmente con la intención de influenciar a una audiencia.

- El término "terrorismo internacional" significa terrorismo que involucra a ciudadanos o al territorio de más de un país.

- El término "grupo terrorista" significa cualquier grupo que practica, o que tiene subgrupos significativos que practican terrorismo internacional.

4. Traducción libre: "Consecuencias fiscales de los conflictos armados y el terrorismo en los países de bajos y medianos ingresos".

5. Traducción libre: "Contrariamente a las expectativas, el final de la Guerra Fría no ha sido un presagio de paz. Ha habido una proliferación de conflictos armados en todo el mundo durante los últimos doce años. En particular, los grupos terroristas se han vuelto cada vez más sofisticados, atrevidos y destructivos".

6. Traducción libre: "Se pueden obtener estimaciones más precisas del impacto del terrorismo en la economía a partir de estudios de conflictos terroristas a más largo plazo (aunque menos intensos). Dichos estudios han tomado dos formas: centrándose en tipos específicos de actividad económica o en la economía de un país específico. Con respecto al primero, Abadie y Gardeazabal (2005) argumentan que el terrorismo afecta la asignación del capital de inversión al aumentar el riesgo y disminuir el rendimiento esperado. Sus estimaciones indican que el aumento del riesgo de terrorismo en un país reduce significativamente la inversión extranjera directa en ese país. Enders y Sandler (1996) también encuentran grandes efectos negativos del terrorismo en la inversión extranjera directa en Grecia y España. Del mismo modo, Enders, Sandler y Parise (1992) encuentran que el terrorismo reduce significativamente el turismo en Grecia, Italia y Austria". 
7. traducción libre: "Dos estudios recientes estiman el efecto del terrorismo en el crecimiento económico en zonas de conflicto particulares. Abadie y Gardeazabal (2003) consideran cómo el terrorismo de ETA ha disminuido el crecimiento económico en el País Vasco de España. Pueden hacerlo porque el terrorismo de ETA se ha concentrado en esta región. Ante esto, construyen estadísticamente un País Vasco "sintético" basado en otras regiones españolas y comparan su crecimiento (libre de terrorismo) con el crecimiento del País Vasco actual. Su análisis sugiere que el terrorismo ETA ha disminuido el PBI per cápita en el País Vasco en 10 puntos porcentuales desde el inicio del terrorismo vasco en la década de 1960. Eckstein y Tsiddon (2004) emplean una metodología de series de tiempo de estilo de intervención para estudiar los efectos de los ataques terroristas en la economía israelí. Encuentran que el terrorismo deprime el crecimiento, pero que los efectos de cualquier ataque son relativamente efímeros".

8. Traducción libre: "Encontramos que los mercados son eficientes al incorporar las noticias de los ataques terroristas y no encuentran evidencia de que los mercados se convirtieran en insensibles a los ataques terroristas a lo largo del tiempo. Nuestra principal conclusión es que los mercados financieros continuaron desempeñando sus funciones económicas de manera eficiente".

9. Traducción libre: "Una gran cantidad de estudios se centran en medir el impacto de los ataques terroristas en toda la economía".

10. Traducción libre: "Eles llegan a la conclusión de que el costo directo para la producción es relativamente pequeño, menor que el costo del conflicto interno, la guerra externa o los desastres naturales".

11. Traducción libre: "No obstante, para poblaciones específicas, regiones y sectores, los efectos adversos pueden ser muy grandes".

12. Traducción libre: "A medida que los terroristas sustituyen entre medios, objetivos y en el tiempo, deben desarrollarse y aplicarse estrategias antiterroristas más allá de la disuasión, como la coordinación multilateral integral".

13. El FATF también es conocido como el Grupo de Acción Financiera sobre Lavado de Dinero (GAFI). En varios estudios se encuentra la sigla FATF-GAFI.

- El Sr. Santiago Otamendi de Argentina asumió el cargo de Presidente del FATF-GAFI el 1 de julio de 2017 con mandato hasta julio 2018.

- Argentina y Brasil integran el FATF.

14. Las Recomendaciones del FAFT-GAFI estan disponibles en: <http://www.fatfgafi.org/publications/fatfrecommendations/documents/internationalstandardsoncombating_moneylaunderingandthefinancingofterrorismproliferation-thefatfrecommendations.html>. Acceso en: 29.10.2017.

\section{REFERENCIAS BIBLIOGRÁFICAS}

BRASIL. Lei Federal 13.260, de 16 de março de 2016. Lei Antiterrorismo (LAT). Disponible en: < $\underline{\text { http:// }}$ www.planalto.gov.br/ccivil_03/_ato2015-2018/2016/lei/l13260.htm>. Acceso en: 10.04.2016.

BRASIL. Decreto ${ }^{0} 5.640$, de 26 de dezembro de 2005. Promulga a Convenção Internacional para Supressão do Financiamento do Terrorismo, adotada pela Assembléia-Geral das Nações Unidas em 9 de dezembro de 1999 e assinada pelo Brasil em 10 de novembro de 2001. Disponible en: <http://www.planalto.gov.br/ccivil_03/_ato20042006/2005/decreto/d5640.htm>. Acceso en: 04.07.2006.

BECKER, Gary. Crime and Punishment: an economic Aprroach. Columbia University, 1968.

BRAUER, Jürgen. On the economics of terrorism. In: Phi Kappa Forum. V. 82. n 2. Spring: 2002. pp 
$38-41$.

CONSEJO DE LA UNIÓN EUROPEA. Decisión Marco 2002/475/JAl, de 13.06.202, sobre la lucha contra el terrorismo. Disponible en: <http://eurlex.europa.eu/legal-content/ES/TXT/ PDF/?uri=CELEX:32002F0475\&from=PT>. Acceso en: 13.05.2004.

CRENSHAW, Martha. The Psichology of Terrorism. In: Political Psychology. 21:2. 2000. pp 406.

ELDOR, Rafi; MELNICK, Rafi. Financial markets and terrorism. Disponible en: <http://rafieldor.co.il/ PDF/Financial\%20markets\%20and\%20terrorism.pdf>. Acceso en: 27.10.2017.

FINANCIAL ACTION TASK FORCE. International Standard son Combating Money Laundering and the Financing of Terrorism \& Proliferation - the FATF Recommendations. Disponible en: $<$ http://www.fatfgafi.org/publications/fatfrecommendations/documents/ $>$.

GOLD, David. Evaluating the Costs and Benefits of the US War on Terror. Disponible en: <http:// www.epsusa.org/events/eea/gold.pdf>. Acceso en: 27.10.2017.

GONÇALVES, Joanisval; REIS, Marcus Vinicius. Terrorismo. Conhecimento e Combate. Niteroi: Impetus. 2016.

GUPTA, Sanjeev; CLEMENTS, Benedict; BHATTACHARYA, Rina; CHAKRAVARTI, Shamit. Fiscal Consequences of Armed Conflict and Terrorism in Low- and Middle-Income Countries. Disponible en: <https://ssrn.com/abstract=879939>. acceso en: 27.10.2017.

INSTITUTE FOR ECONOMICS \& PEACE. Global terrorism index 2015. Disponible en: <http:// economicsandpeace.org/wp-content/uploads/2015/11/Global-Terrorism-Index-2015.pdf>. Acceso en: 11.04.2016.

LLUSSÁ, Fernanda; TAVARES, José. The economics of terrorism: a synopsis. Disponible en: <file:///C:/Users/Usu\%C3\%A1 rio/Desktop/Terrorismo/Fernanda\%20-\%20The\%20economics\%20of\%20 terrorism\%20-\%20synopsis.pdf>. Acceso en: 27 oct. 2017.

MESQUITA, Ethan Bueno. The Political Economy of Terrorism: A Selective Overview of Recent Work. Disponible en: <file:///C:/Users/Usu\%C3\%A1rio/Desktop/Terrorismo/Ethan\%20Bueno\%20\%20 Political\%20Economy\%20of\%20Terrorism.pdf>. Acceso en: 27.10.2017.

MOHAMMED El-Qorchi. The Hawala System. Disponible en: <http://www.gdrc.org/icm/hawala.html>. Acceso en: 28.10.2017.

ORGANIZACIÓN DE LAS NACIONES UNIDAS. Resolución 49/60, Asamblea General, 09.12.1994. Medidas para Eliminar el Terrorismo Internacional. Disponible en: <http://www.un.org/es/comun/ docs/?symbol=A/RES/49/60\&Lang=S $>$. Acceso en: 17.08.2005.

ORGANIZACIÓN DE LAS NACIONES UNIDAS. International Convention for the Suppression of the Financing of Terrorism. 09.12.1999. Disponible en: <http://www.un.org/en/sc/ctc/docs/conventions/ Conv12.pdf> acceso en: 17.08.2005.

ORGANIZACIÓN DE LAS NACIONES UNIDAS. Resolución 1566/2004, Consejo de Seguridad. 08.10.2004. Disponible en: <http://www.un.org/es/comun/docs/?symbol=S/RES/1566\%20\%282004\%29>. 
Acceso en: 17.08.2005.

PILLAR, Paul R. The dimensions of terrorism and counterterrorism. In: Terrorism and the United States foreign policy. The Brookings Institution: 2001. pp 19-29.

SINAI, Joshua. How to define terrorism. In: Perspectives on terrorismo. v II. Issue 4, February 2008. pp 9-11.

VIAPIANA, Luiz Tadeu. Economia do Crime. Uma explicação para a formação do criminoso. Porto Alegre: AGE. 2006.

Este artículo refleja únicamente la opinión del autor y no puede ser vinculado a las Instituciones que trabaja o que ha trabajado. 